\title{
Mitogen-Activated Protein Kinase Cascade in the Basolateral Nucleus of Amygdala Is Involved in Extinction of Fear-Potentiated Startle
}

\author{
Kwok-Tung Lu, David L. Walker, and Michael Davis \\ Department of Psychiatry and Behavioral Science, Emory University, Atlanta, Georgia 30322
}

Previous results indicate that intra-amygdala infusions of NMDA receptor antagonists block the extinction of conditioned fear. Mitogen-activated protein kinase (MAPK) can be activated by NMDA receptor stimulation and is involved in excitatory fear conditioning. Here, we evaluate the role of MAPK within the basolateral amygdala in the extinction of conditioned fear.

Rats received 10 light-shock pairings. After $24 \mathrm{hr}$, fear was assessed by eliciting the acoustic startle reflex in the presence of the conditioned stimulus (CS) (CS-noise trials) and also in its absence (noise-alone trials). Rats subsequently received an intra-amygdala or intrahippocampal infusion of either $20 \%$ DMSO or the MAPK inhibitor PD98059 (500 ng/side) followed 10 min later by 30 presentations of the light CS without shock (extinction training). After $24 \mathrm{hr}$, they were again tested for fear-potentiated startle. PD98059 infusions into the basolateral amygdala but not the hippocampus significantly reduced extinction, which was otherwise evident in DMSO-infused rats. Control experiments indicated that the effect of intra-amygdala PD98059 could not be attributed to lasting damage to the amygdala or to state dependency. These results suggest that a MAPK-dependent signaling cascade within or very near the basolateral amygdala plays an important role in the extinction of conditioned fear.

Key words: amygdala; hippocampus; extinction; fear conditioning; fear-potentiated startle; mitogen-activated protein kinase
Mitogen-activated protein kinase (MAPK) is a serine-threonine kinase that is widely expressed in cell bodies and dendrites of postmitotic neurons (Boulton et al., 1991; Fiore et al., 1993). Although a role for MAPK in cell growth and proliferation has been known for some time (cf. Neary, 1997), recent evidence has pointed to an additional involvement of MAPK in the neuroplasticity that underlies learning (cf. Impey et al., 1999). For example, Schafe et al. (1999) reported that pretraining intraventricular infusions of the MAPK inhibitor PD98059 markedly impaired contextual fear conditioning and also impaired, albeit to a lesser degree, discrete cue conditioning to an auditory conditioned stimulus (CS). The same inhibitor has also been found to disrupt long-term potentiation (LTP) in the hippocampal formation (English and Sweatt, 1997; S. Davis et al., 2000) and in the lateral nucleus of the amygdala (Huang et al., 2000). Also, Brambilla et al. (1997) reported that knock-out mice lacking Ras guanine nucleotide exchange factor, an MAPK activator, show a profound disruption not only of avoidance learning and of cued and contextual fear conditioning but also of amygdala LTP.

From the standpoint of fear conditioning, evidence for an involvement of MAPK in amygdala plasticity is particularly interesting. It has long been recognized that the amygdala is involved in emotional processes, and considerable evidence points

Received April 9, 2001; revised June 11, 2001; accepted June 11, 2001.

This work was supported by National Institute of Mental Health Grants MH 47840, MH 57250, MH 58922, MH 52384, and MH 59906, by the Woodruff Foundation, and by the Science and Technology Centers program (The Center for Behavioral Neuroscience) of the National Science Foundation under Agreement No. IBN-9876754.

Correspondence should be addressed to Dr. Michael Davis, Department of Psychiatry and Behavioral Science, Emory University School of Medicine, Woodruff Memorial Building Suite 4000, 1639 Pierce Drive, Atlanta, GA 30322. E-mail: mdavis4@emory.edu.

Copyright () 2001 Society for Neuroscience $0270-6474 / 01 / 210001-05 \$ 15.00 / 0$ to the basolateral complex of the amygdala as an important site of plasticity for both the development and extinction of fear memories (cf. Aggleton, 2000). With respect to the latter, Falls et al. (1992) reported that intra-amygdala infusion of the NMDA receptor antagonist AP-5 made just before extinction training (i.e., nonreinforced cue presentations) prevented extinction as assessed with fear-potentiated startle. Lee and Kim (1998) reported that intra-amygdala administration of AP-5 also blocked extinction when freezing was used as a measure of fear and when auditory, visual, or contextual CSs were used as conditioned fear stimuli.

Given evidence that (1) amygdala NMDA receptors are involved in the extinction of conditioned fear, (2) MAPK is activated by NMDA receptor stimulation (English and Sweatt, 1996; Xia et al., 1996), and (3) amygdala MAPK is involved in both excitatory fear conditioning and amygdala LTP, we evaluated the role of amygdala MAPK in the extinction of conditioned fear. To do this, the MAPK inhibitor PD98059 was infused directly into the amygdala just before extinction training (experiment 1). As an anatomical control, and in view of evidence implicating the

This article is published in The Journal of Neuroscience, Rapid Communications Section, which publishes brief, peerreviewed papers online, not in print. Rapid Communications are posted online approximately one month earlier than they would appear if printed. They are listed in the Table of Contents of the next open issue of JNeurosci. Cite this article as: JNeurosci, 2001, 0:RC162 (1-5). The publication date is the date of posting online at www.jneurosci.org.

http://www.jneurosci.org/cgi/content/full/5555 
hippocampus in extinction for some tasks but not others (cf. M. Davis et al., 2000), PD90059 was also infused into the hippocampus (experiment 2). In experiment 3, we controlled for statedependent drug effects by infusing PD98059 before both extinction training and extinction testing.

\section{MATERIALS AND METHODS}

\section{Animals}

Male Sprague Dawley rats (300-400 gm; Charles River, Raleigh, NC) were housed in groups of four before surgery and housed singly after surgery. Food and water were available ad libitum. The vivarium was kept on a $12 \mathrm{hr}$ light/dark cycle with lights on at 07:00 A.M. Behavioral procedures took place during the animal's light cycle.

\section{Apparatus}

Animals were trained and tested in $8 \times 15 \times 15 \mathrm{~cm}$ Plexiglas and wire-mesh cages. The cage floor consisted of four 6.0 -mm-diameter stainless steel bars spaced $18 \mathrm{~mm}$ apart. Each cage was suspended between compression springs within a steel frame and located within a custom-designed $90 \times 70 \times 70 \mathrm{~cm}$ ventilated sound-attenuating chamber. Background noise ( $60 \mathrm{~dB}$ wide-band) was provided by a General Radio Type 1390-B noise generator (Concord, MA) and delivered through high-frequency speakers (Radio Shack Supertweeter; Tandy, Fort Worth, $\mathrm{TX}$ ) located $5 \mathrm{~cm}$ from the front of each cage.

Startle responses were evoked by $50 \mathrm{msec}, 95 \mathrm{~dB}$ white-noise bursts $(5$ msec rise-decay) generated by a Macintosh G3 computer soundfile $(0-22 \mathrm{kHz})$, amplified by a Radio Shack amplifier (100 W; model MPA200; Tandy), and delivered through the same speakers used to provide background noise. Sound pressure levels were measured using a Bruel \& Kjaer (Marlborough, MA) model 2235 sound-level meter (A scale; random input) with the microphone (type 4176) held $7 \mathrm{~cm}$ from the speaker (approximating the distance of the rat's ear from the speaker).

An accelerometer (model U321AO2; PCB Piezotronics, Depew, NY) affixed to the bottom of each cage produced a voltage output proportional to the velocity of cage movement. This output was amplified (model 483B21; PCB Piezotronics) and digitized on a scale of $0-2500 \mathrm{U}$ by an InstruNET device (model 100B; GW Instruments, Somerville, MA) interfaced to a Macintosh G3 computer. Startle amplitude was defined as the maximal peak-to-peak voltage that occurred during the first $200 \mathrm{msec}$ after onset of the startle-eliciting stimulus.

The CS was a $3.7 \mathrm{sec}$ light produced by an $8 \mathrm{~W}$ fluorescent bulb (100 $\mu \mathrm{sec}$ rise time) located $10 \mathrm{~cm}$ behind each cage. Light intensity at the center of the test cage was 82 lux as measured with a VWR light meter (VWR Scientific, Atlanta, GA). The unconditioned stimulus (a $0.5 \mathrm{sec}$, $0.4 \mathrm{~mA}$ floorbar shock) was produced by a LeHigh Valley shock generator (SGS-004; LeHigh Valley, Beltsville, MD). Shock intensity was measured as described by Cassella and Davis (1986).

\section{Surgery}

Rats were anesthetized with Nembutal (sodium pentobarbital, $50 \mathrm{mg} / \mathrm{kg}$, i.p.) and placed in a Kopf stereotaxic instrument (David Kopf Instruments, Tujunga, CA). We then implanted 22 gauge guide cannulas (model C313G; Plastic Products, Roanoke, VA) into the basolateral nucleus of the amygdala [anteroposterior (AP), -2.8 ; dorsoventral (DV), -9.0 ; mediolateral (ML), \pm 5.0 from bregma] or dorsal hippocampus (AP, $-4.6 ; \mathrm{DV}, \pm 4.0 ; \mathrm{ML}, \pm 3.2$ ). Size 0 insect pins (Carolina Biological Supply, Burlington, NC) were inserted into each cannula to prevent clogging. Screws were anchored to the skull and the assembly was cemented in place using dental cement (Plastic Products).

\section{Drug infusion}

PD98059 (500 ng in $1 \mu \mathrm{l}$ of 20\% DMSO; Calbiochem, La Jolla, CA) or $20 \%$ DMSO was infused $(0.25 \mu \mathrm{l} / \mathrm{min})$ through 28 gauge injection cannulas (model C313I; Plastic Products) 10 min before extinction training. This dose was chosen on the basis of pilot data and Western blot analyses performed by Blum et al. (1999) showing that intrahippocampal inf usions of a slightly higher dose $(2 \mu \mathrm{g})$ disrupt MAPK phosphorylation without noticeably influencing the phosphorylation of several other kinases (e.g., protein kinase A, protein kinase $\mathrm{C}$, and calcium-calmodulindependent protein kinase).

\section{Behavioral procedures}

The behavioral procedure consisted of the following phases: acclimation, initial startle test, fear conditioning, pre-extinction test, nonreinforced cue exposure (i.e., extinction training), and post-extinction test (also see Fig. 1 timelines).

Acclimation. On 3 consecutive days, rats were placed in the startle test boxes and returned to their home cage after $10 \mathrm{~min}$.

Initial startle test. On 2 consecutive days, animals were placed in the startle cages and presented with 30 startle stimuli using an intertrial interval (ITI) of $30 \mathrm{sec}$.

Training. Rats were returned to the startle cages and 5 min later received the first of 10 light-shock pairings. Shocks were delivered during the last $0.5 \mathrm{sec}$ of the $3.7 \mathrm{sec}$ CS. The average ITI was $4 \mathrm{~min}$ (range, 3-5 $\mathrm{min}$ ).

Pre-extinction test. Rats were placed in the startle cages and, after 5 min, presented with 30 startle-eliciting noise bursts. These initial startle stimuli (hereafter referred to as "leaders") were used to habituate the startle response to a stable baseline. Thirty seconds after the final leader stimulus, each animal received 10 startle-eliciting noise bursts presented alone (noise-alone trial) and 10 noise bursts presented $3.2 \mathrm{sec}$ after onset of the $3.7 \mathrm{sec}$ CS (CS-noise trials). The two trial types were presented in a balanced mixed order (ITI, $30 \mathrm{sec}$ ). For each rat, the percentage of fear-potentiated startle was computed as follows: [(startle amplitude on CS-noise minus noise-alone trials)/(noise-alone trials) $] \times 100$. Using these scores, rats were assigned to two groups such that each group had equivalent mean levels of fear-potentiated startle.

Extinction training (nonreinforced cue exposure). Rats were returned to the startle cages and given 30 presentations of the CS without shock 5 min later (ITI, $30 \mathrm{sec}$ ). This extinction procedure was repeated $24 \mathrm{~h}$ later.

Post-extinction test. Rats were placed in the startle cages and presented 5 min later with 18 leader stimuli followed by 30 noise-alone and 30 CS-noise trials (presented in a balanced irregular order with a $30 \mathrm{sec}$ ITI). The larger number of CS trials was used here, compared with the pre-extinction test, for two reasons. First, the fear-potentiated startle test is itself an extinction procedure (i.e., nonreinforced CS presentations), and we wanted to minimize, in the pre-extinction test, any incidental extinction that might occur. Second, the primary statistical comparison of interest is between drug- and vehicle-infused rats after extinction. The greater number of test trials on the post-extinction test allows for a more sensitive statistical analysis of this comparison. This also provides a greater opportunity for within-session extinction. However, the statistical impact of this is minimal insofar as both groups are equally susceptible, on noninfusion test days, to within-session extinction.

Test for toxicity. If extinction was disrupted by PD98059 (and the corresponding control group), rats were given two additional extinction training sessions without drug, followed $24 \mathrm{~h}$ later by a second postextinction test. A finding that extinction could still occur would suggest that the previously observed disruption of extinction was not attributable to amygdala toxicity.

Test for state dependency. Because pharmacological disruption of extinction has sometimes been attributed to state-dependent learning (Bouton et al., 1990), it is possible that rats infused with PD98059 during extinction training would not show evidence of extinction when subsequently tested without drug. To evaluate this possibility, additional rats were trained and tested as described previously. However, $24 \mathrm{~h}$ after post-extinction test 1 , rats received a second infusion of the same compound that they had received during extinction training (i.e., either DMSO or PD98059) and were tested again 10 min later for fearpotentiated startle (i.e., post-extinction test 2).

\section{Histology}

Rats were overdosed with chloral hydrate and perfused intracardially with $0.9 \%$ saline followed by $10 \%$ formalin. The brains were removed and immersed in a $30 \%$ sucrose-formalin solution for at least $3 \mathrm{~d}$. Coronal sections $(30 \mu \mathrm{m})$ were cut through the area of interest, stained with cresyl violet, and examined under light microscope for cannula placement.

\section{Statistics}

The mean startle amplitude on noise-alone and CS-noise trials was calculated for each animal. The percentage of fear-potentiated startle was computed as [(startle amplitude on CS-noise minus noise-alone trials)/(noise-alone trials) $] \times 100$. Between-group comparisons were made using $t$ tests for independent samples. Within-group comparisons (e.g., pre-extinction vs post-extinction) were evaluated using $t$ tests for paired samples. In experiment 3 , ANOVA was used to evaluate the effect of session (post-extinction test 1 vs post-extinction test 2) and treatment 
(DMSO vs PD98059). The criterion for significance for all comparisons was $p<0.05$ (two-tailed $t$ test).

\section{RESULTS}

\section{Histology}

Behavioral data from 10 animals were excluded from the statistical analyses of experiments 1 and 3 because of missed placements (defined as $\geq 0.5 \mathrm{~mm}$ from the basolateral complex of the amygdala) or because of complications with the drug infusion. Placements for the remaining animals are shown in Figure 1.

\section{Intra-amygdala infusion of the MAPK inhibitor PD98059 blocks the extinction of fear conditioning}

Behavioral data for animals that received intra-amygdala infusions are shown in Figure $1 A$. For rats infused with DMSO $(n=$ 8 ), fear-potentiated startle was significantly lower during the post-extinction test compared with the pre-extinction test $\left(_{(7)}=\right.$ 2.364; $p<0.05)$. In contrast, fear-potentiated startle in animals infused with PD98059 $(n=8)$ was comparable with and not significantly different from their pre-extinction level $t_{(7)}=0.23$; $p=0.82)$. The level of fear-potentiated startle after nonreinforced cue exposure was significantly lower in the DMSO group versus the PD98059 group $\left(t_{(14)}=2.51 ; p<0.05\right)$. In short, intra-amygdala infusions of PD98059 blocked extinction.

To test for toxicity, all animals received an additional $2 \mathrm{~d}$ of drug-free extinction training and were retested $24 \mathrm{~h}$ later. Under these conditions, animals previously infused with PD98059 did show a significant reduction of fear-potentiated startle from postextinction test 1 to post-extinction test $2\left(t_{(7)}=2.518 ; p<0.05\right)$ (Fig. 1A). Thus, the blockade of extinction observed during post-extinction test 1 appeared to result from an acute drug effect rather than from a more permanent, perhaps toxic action of PD98059, especially because previous studies have shown that lesions of the basolateral amygdala block fear-potentiated startle (Sananes and Davis, 1992; Campeau and Davis, 1995), an outcome opposite in direction from that obtained with PD98059 inf usions.

\section{Intrahippocampal infusions of PD98059 do not block extinction of fear conditioning}

Behavioral data for animals that received intrahippocampal infusions are shown in Figure $1 B$. Fear-potentiated startle in the DMSO versus PD98059 groups did not significantly differ from one another either before or after cue exposure. In both groups, fear-potentiated startle was significantly lower during the postextinction test than during the pre-extinction test $\left(t_{(6)}=2.78 ; p<\right.$ 0.05 and $t_{(7)}=2.58 ; p<0.05$ for the DMSO and PD98098 groups, respectively). Thus, PD98059 did not disrupt extinction when infused into the dorsal hippocampus.

\section{The disruptive effect of intra-amygdala PD98059 infusions is not attributable to state dependency}

To evaluate the possible contribution of state-dependent drug effects to the results obtained in experiment 1, additional amygdala-cannulated rats were tested for extinction in a drug-free state and subsequently after receiving the same compound that they had received during extinction training. These results are shown in Figure $1 C$. For control rats $(n=8)$, fear-potentiated startle was significantly lower during post-extinction test 1 compared with the pre-extinction test $\left(t_{(7)}=2.364 ; p<0.05\right)$. In contrast, the level of fear-potentiated startle in animals infused with PD98059 $(n=8)$ was comparable with and not significantly different from their pre-extinction level. In addition, the level of fear-potentiated startle after cue exposure was significantly lower in the control group versus the PD98059 group $\left(t_{(14)}=2.179 ; p<\right.$ $0.05)$. Thus, these results replicate the principal finding of experiment 1.

Rats infused with PD98095 before post-extinction test 2 showed a loss of fear-potentiated startle from post-extinction test 1 to post-extinction test 2 . Vehicle-inf used rats showed a comparable loss. Statistically, an ANOVA using session and treatment as within- and between-subject factors, respectively, indicated significant session $\left(F_{(1,14)}=17.232 ; p<0.01\right)$ and treatment $\left(F_{(1,14)}=20.087 ; p<0.01\right)$ effects but not a significant interaction. The loss of fear-potentiated startle in both groups probably reflects incidental extinction produced by the 30 nonreinforced CS presentations of post-extinction test 1 . The failure of rats inf used with the MAPK inhibitor before testing to show a loss of fearpotentiated startle beyond that which could be attributed to this incidental extinction suggests that state dependency is not a major factor in accounting for the previously described effects of PD98095.

\section{DISCUSSION}

Previous findings have shown that MAPK inhibitors retard acquisition in a variety of learning paradigms. In addition to previously mentioned effects on discrete cue and contextual fear conditioning (Schafe et al., 1999) after intraventricular administration, MAPK inhibitors have been shown to disrupt taste aversion learning when infused into the insular cortex (Berman et al., 1998), avoidance learning when infused into the amygdala, hippocampus, entorhinal, or parietal cortices (Walz et al., 1999a,b, 2000), and spatial learning with the Morris water maze after either systemic or intrahippocampal administration (Blum et al., 1999; Selcher et al., 1999).

Here we show that the MAPK pathway is also involved in extinction. Specifically, intra-amygdala infusion of the MAPK inhibitor PD98059 blocked the extinction of conditioned fear as assessed with fear-potentiated startle. This could not be attributed either to lasting damage to the amygdala (because conditioned fear did extinguish in animals previously given PD98059 when the extinction procedure was repeated without drug) or to state-dependent drug effects. Moreover, the effects were anatomically specific. Intrahippocampal infusions did not disrupt extinction.

These results are compatible with an emerging appreciation for the role of the amygdala in the extinction of conditioned fear. As noted previously, Falls et al. (1992) reported that intra-amygdala infusions of the NMDA receptor antagonist AP-5 blocked extinction as assessed with fear-potentiated startle, and Lee and Kim (1998) reported similar results using freezing as a measure of fear. Using functional magnetic resonance imaging, LaBar et al. (1998) noted amygdala activation during both the acquisition and extinction phase of discriminative fear conditioning in humans.

These results are also compatible with the view that fear acquisition and fear extinction are forms of learning with at least partially similar neuroanatomical substrates and pharmacologies. As with extinction, fear acquisition can also be disrupted by MAPK inhibitors (Schafe et al., 1999; our current results) (although see Berman and Dudai, 2001) and by intra-amygdala infusion of NMDA receptor antagonists (Miserendino et al., 1990). In fact, evidence that MAPK is activated by NMDA receptor stimulation suggests that these two sets of observations may be causally linked. In particular, extinction training may activate amygdala NMDA receptors, which in turn may activate 

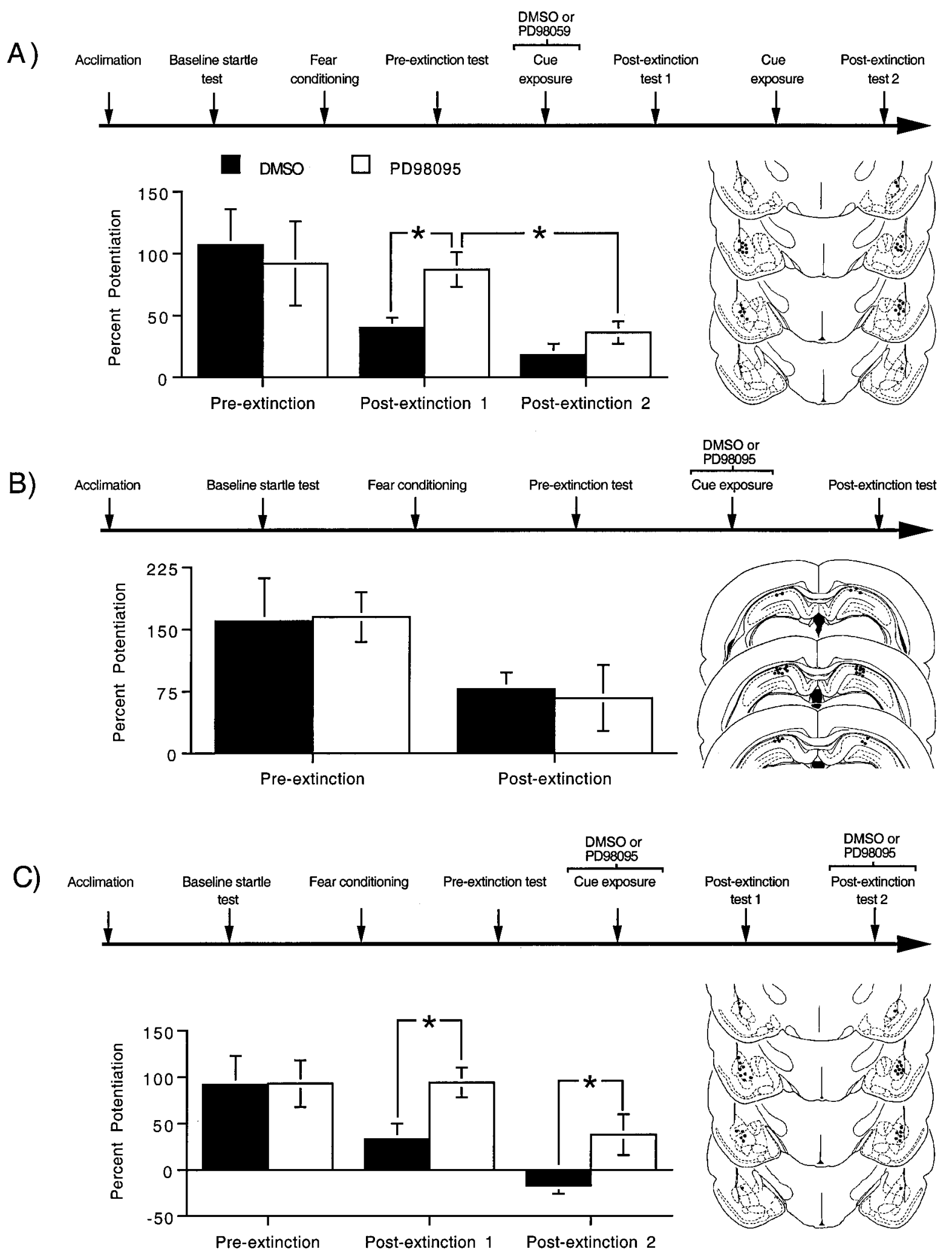

Figure 1. For each panel, an experimental timeline is shown at the top, experimental data are shown at the bottom, and cannula tip locations [transcribed onto atlas plates modified from Paxinos and Watson (1997)] are shown to the right. In experiment $1(A)$, animals were tested for fear-potentiated startle before (Pre-extinction test) and after (Post-extinction test 1) nonreinforced cue exposure (extinction training). Before extinction training, rats received intra-amygdala infusions of either PD98095 or the DMSO vehicle. PD98059 blocked extinction learning. These same animals showed normal extinction after nonreinforced cue exposure without drug (Post-extinction test 2). The effects were anatomically specific. PD98059 did not block extinction learning when infused into the dorsal hippocampus (experiment $2 ; B$ ). The disruptive effect of amygdala MAPK inhibition could not be readily attributed to state dependence. In experiment $3(C)$, rats received extinction training after intra-amygdala inf usions of DMSO or PD98095. As expected, PD98095 blocked extinction learning (Post-extinction test 1). When retested (Post-extinction test 2) after an infusion of the same compound that they had received during extinction training, PD98095-infused rats continued to show significantly higher levels of fear-potentiated startle than vehicle-infused rats. ${ }^{*} p<0.05$. 
MAPK, which in turn is required for extinction. It is alternatively possible that intra-amygdala PD98059 infusions decrease tonic MAPK activity levels below a critical threshold required for extinction. However, evidence that MAPK activity increases after behavioral training and also after LTP induction (Atkins et al., 1998; Berman et al., 1998; Blum et al., 1999; S. Davis et al., 2000), and that this activation is NMDA receptor-dependant (Cammarota et al., 2000), is perhaps more consistent with the former possibility.

The exact role that amygdala MAPK plays in extinction is unclear. In general, the prominent role of this kinase in genomic regulation (Seger and Krebs, 1995; Impey et al., 1999; S. Davis et al., 2000) suggests that the MAPK pathway participates in the synthesis of proteins important for the long-term stabilization and storage of fear memories. Consistent with this possibility, treatments that interfere with MAPK function have been found to have their greatest effects on long- but not short-term retention in behavioral studies (Brambilla et al., 1997; Martin et al., 1997; Blum et al., 1999; Schafe et al., 1999; Walz et al., 1999b) and on late-stage but not early-stage potentiation in electrophysiological studies (Brambilla et al., 1997; Huang et al., 2000). However, differential effects of MAPK and other treatments on shortversus long-term memory, although often attributed to selective effects on different phases of memory storage, may sometimes be attributed to parametric differences in the strength of the conditioned response and therefore its susceptibility to disruption at short- versus long-train test intervals (Walker and Davis, 2000). Additional experiments will be necessary to resolve this issue with respect to MAPK and the extinction of conditioned fear.

\section{REFERENCES}

Aggleton JP (2000) The amygdala, Vol 2. Oxford: Oxford UP.

Atkins CM, Selcher JC, Petraitis JJ, Trzaskos JM, Sweatt JD (1998) The MAPK cascade is required for mammalian associative learning. Nat Neurosci 1:602-609.

Berman D, Dudai Y (2001) Memory extinction, learning anew, and learning the new: dissociations in the molecular machinery of learning in cortex. Science 291:2417-2419.

Berman DE, Hazvi S, Rosenblum K, Seger R, Dudai Y (1998) Specific and differential activation of mitogen-activated protein kinase cascades by unfamiliar taste in the insular cortex of the behaving rat. J Neurosci 18:10037-10044.

Blum S, Moore AN, Adams F, Dash PK (1999) A mitogen-activated protein kinase cascade in the CA1/CA2 subfield of the dorsal hippocampus is essential for long-term spatial memory. J Neurosci 19:3535-3544.

Boulton TG, Nye SH, Robbins DJ, Ip NY, Radziejewska E, Morgenbesser SD, DePinho RA, Panayotatos N, Cobb MH, Yancopoulos GD (1991) ERKs: a family of protein-serine/threonine kinases that are activated and tyrosine phosphorylated in response to insulin and NGF. Cell 65:663-675.

Bouton ME, Kenney FA, Rosengard C (1990) State-dependent fear extinction with two benzodiazepine tranquilizers. Behav Neurosci 104:44-55.

Brambilla R, Gnesutta N, Minichiello L, White G, Roylance AJ, Herron CE, Ramsey M, Wolfer DP, Cestari V, Rossi-Arnaud C, Grant SG, Chapman PF, Lipp HP, Sturani E, Klein R (1997) A role for the Ras signalling pathway in synaptic transmission and long-term memory. Nature 390:281-285.

Cammarota M, Bevilaqua LR, Ardenghi P, Paratcha G, Levi de Stein M, Izquierdo I, Medina JH (2000) Learning-associated activation of nuclear MAPK, CREB, and Elk-1, along with Fos production, in the rat hippocampus after one-trial avoidance learning: abolition by NMDA receptor blockade. Brain Res Mol Brain Res 76:36-46.

Campeau S, Davis M (1995) Involvement of the central nucleus and basolateral complex of the amygdala in fear conditioning measured with fear-potentiated startle in rats trained concurrently with auditory and visual conditioned stimuli. J Neurosci 15:2301-2311.

Cassella JV, Davis M (1986) Habituation, prepulse inhibition, fear con- ditioning, and drug modulation of the acoustically elicited pinna reflex in rats. Behav Neurosci 100:39-44.

Davis M, Falls WA, Gewirtz J (2000) Neural systems involved in fear inhibition: extinction and conditioned inhibition. In: Contemporary issues in modeling psychopathology (Myslobodsky M, Weiner I, eds), pp 113-142. Boston: Kluwer.

Davis S, Vanhoutte P, Pages C, Caboche J, Laroche S (2000) The MAPK/ERK cascade targets both Elk-1 and cAMP response elementbinding protein to control long-term potentiation-dependent gene expression in the dentate gyrus in vivo. J Neurosci 20:4563-4572.

English JD, Sweatt JD (1996) Activation of p42 mitogen-activated protein kinase in hippocampal long-term potentiation. J Biol Chem 271:24329-24332.

English JD, Sweatt JD (1997) A requirement for the mitogen-activated protein kinase cascade in hippocampal long-term potentiation. J Biol Chem 272:19103-19106.

Falls WA, Miserendino MJD, Davis M (1992) Extinction of fearpotentiated startle: blockade by infusion of an NMDA antagonist into the amygdala. J Neurosci 12:854-863.

Fiore RS, Bayer VE, Pelech SE, Posada J, Cooper JA, Baraban JM (1993) p42 mitogen-activated protein kinase in brain: prominent localization in neuronal cell bodies and dendrites. Neuroscience 55:463-472.

Huang YY, Martin KC, Kandel ER (2000) Both protein kinase A and mitogen-activated protein kinase are required in the amygdala for the macromolecular synthesis-dependent late phase of long-term potentiation. J Neurosci 20:6317-6325.

Impey S, Obrietan K, Storm DR (1999) Making new connections: role of ERK/MAP kinase signaling in neuronal plasticity. Neuron 23:11-14.

LaBar KS, Gatenby JC, Gore JC, LeDoux JE, Phelps EA (1998) Human amygdala activation during conditioned fear acquisition and extinction: a mixed-trial fMRI study. Neuron 20:937-945.

Lee H, Kim J (1998) Amygdalar NMDA receptors are critical for new fear learning in previously fear-conditioned rats. J Neurosci 18:8444-8454

Martin KC, Michael D, Rose JC, Barad M, Casadio A, Zhu H, Kandel ER (1997) MAP kinase translocates into the nucleus of the presynaptic cell and is required for long-term facilitation in Aplysia. Neuron 18:899-912.

Miserendino MJD, Sananes CB, Melia KR, Davis M (1990) Blocking of acquisition but not expression of conditioned fear-potentiated startle by NMDA antagonists in the amygdala. Nature 345:716-718.

Neary JT (1997) MAPK cascades in cell growth and death. News Physiol Sci 12:286-293.

Paxinos G, Watson C (1997) The rat brain in stereotaxic coordinates, Ed 3. New York: Academic.

Sananes CB, Davis M (1992) N-methyl-D-aspartate lesions of the lateral and basolateral nuclei of the amygdala block fear-potentiated startle and shock sensitization of startle. Behav Neurosci 106:72-80.

Schafe GE, Nadel NV, Sullivan GM, Harris A, LeDoux JE (1999) Memory consolidation for contextual and auditory fear conditioning is dependent on protein synthesis, PKA, and MAP kinase. Learn Mem 6:97-110.

Seger R, Krebs EG (1995) The MAPK signaling cascade. FASEB J 9:726-735.

Selcher JC, Atkins CM, Trzaskos JM, Paylor R, Sweatt JD (1999) A necessity for MAP kinase activation in mammalian spatial learning. Learn Mem 6:478-490.

Walker DL, Davis M (2000) Involvement of $N$-methyl-D-aspartate (NMDA) receptors within the amygdala in short- versus long-term memory for fear conditioning as assessed with fear-potentiated startle. Behav Neurosci 114:1019-1033.

Walz R, Roesler R, Quevedo J, Rockenbach IC, Amaral OB, Vianna MR, Lenz G, Medina JH, Izquierdo I (1999a) Dose-dependent impairment of inhibitory avoidance retention in rats by immediate post-training infusion of a mitogen-activated protein kinase kinase inhibitor into cortical structures. Behav Brain Res 105:219-223.

Walz R, Roesler R, Barros DM, de Souza MM, Rodrigues C, Sant'Anna MK, Quevedo J, Choi HK, Neto WP, DeDavid e Silva TL, Medina JH, Izquierdo I (1999b) Effects of post-training infusions of a mitogenactivated protein kinase kinase inhibitor into the hippocampus or entorhinal cortex on short- and long-term retention of inhibitory avoidance. Behav Pharmacol 10:723-730.

Walz R, Roesler R, Quevedo J, Sant'Anna MK, Madruga M, Rodrigues C, Gottfried C, Medina JH, Izquierdo I (2000) Time-dependent impairment of inhibitory avoidance retention in rats by post-training infusion of a mitogen-activated protein kinase kinase inhibitor into cortical and limbic structures. Neurobiol Learn Mem 73:11-20.

Xia X, Dudek H, Miranti CK, Greenberg ME (1996) Calcium influx via the NMDA receptor induces immediate early gene transcription by a MAP kinase/ERK-dependent mechanism. J Neurosci 16:5425-5436. 